Vol. 5, No. 1, 2020

\title{
HANDLING THE PHARMACEUTICAL INDUSTRY WASTE IN UKRAINE AND THE UA
}

\author{
Olena Popovych, Nataliya Vronska, Yuriy Yatchyshyn, Yaroslava Zaharko \\ Lviv Polytechnic National University, \\ 12, S. Bandery Str., Lviv, 79013, Ukraine \\ lpolenaeko@yahoo.com
}

https://doi.org/10.23939/ep2020.01.050

Received: 10.02 .2020

(C) Popovych O., Vronska N., Yatchyshyn Yu., Zaharko Ya., 2020

\begin{abstract}
The prospects of the pharmaceutical industry development are closely connected with scientific and technological progress. In Ukraine, handling hazardous medical waste is an open question. The rapid development of pharmacy in recent years has created and increased the possibility of the generation and accumulation of pharmaceutical waste at the enterprises and in the environment. Only a few enterprises deal with medical waste disposal. Medical waste recycling requires an extremely high level of attention and carries great risks associated with handling this medical waste. When medical waste is burnt, strong pollutants are released into the atmosphere - carcinogens, furans and dioxins from chlorine halogen compounds, namely dumping of the hazardous material that contains heavy metals, and is likely to cause bioaccumulative hazardous substances to transfer to the environment.
\end{abstract}

Key words: medical and pharmaceutical waste, medicines, concentration, purification, methods, packaging, disposal, processing.

\section{Introduction}

At present, the whole world is faced with the problem of waste disposal in the pharmaceutical industry due to anthropogenic changes occurring in the environment.

When left in public landfills, infected residues of medicines and medical devices are a direct threat to humans, especially children.

The problem of disposal and decontamination of pharmaceutical waste generated by the population has not been solved in Ukraine yet. Such waste should be disinfected and burned, rather than simply utilized at the available landfills intended for household waste.

The purpose of the paper is to analyze handling waste of the pharmaceutical industry in Ukraine and the EU countries, the ways of their recycling and disposal, as well as the appearance of pharmaceutical contamination in wastewater and methods of its purification.

\section{Analysis of the reference data}

Handling pharmaceutical industry waste in Ukraine is governed by several laws and regulations. According to the Law of Ukraine "On Medicines", it is defined that low-quality medicines, including the expired and counterfeit ones, are subject to immediate disposal and destruction. The Ministry of Healthcare of Ukraine approved "Rules of conducting disposal and destruction of low-quality medicines" on July 8, 2004. Despite the subsidiary law, handling medical waste is extremely poor.

If we talk about the waste of the pharmaceutical industry, it is divided into medical and pharmaceutical one.

For the safe disposal of medical waste of 4 hazard classes, a variety of colour packages is used to collect them. The packaging of disinfected medical waste must have a marking that indicates the main process - disinfection of this waste. It is forbidden to export medical waste that has not undergone a preliminary disinfection test outside the health care facility. Specialized organizations that deal with the disposal of medical waste transport this waste from the facilities where it was generated to the place of its safe disposal.

Pharmaceutical waste from medical establishments and pharmacies, in case of detection of adverse properties, exceedance of the expiration date or damage of medicines, should be returned to the manufacturer who must necessarily destroy these pharmaceuticals by removing them from circulation at their own expense or 
involve another licensed organization for treatment and disposal of low-quality pharmaceutical products.

Pharmaceutical waste disposal is a very important process. It involves physical, chemical, biological, and mechanical treatment, burning or even disposal in the designated areas after determining the hazard class and type of waste.

The population is not informed about the danger that can be caused by the misuse of medical waste. People have no information about possible methods of disposal of low-quality and expired medicines at home. There are no conditions for receiving pharmaceutical waste generated by the population for its further transfer to the relevant entities licensed for hazardous waste operations.

The nation's health is the most important socioeconomic resource of the society and the priority social value in the developed countries and the countries developing rapidly, so the pharmaceutical industry in these countries belongs to the high-tech and sciencedriven sectors of the economy.

A characteristic feature of the EU pharmaceutical market is that in the structure of the EU countries' pharmaceutical markets (even among the largest world producers), the import indicators exceed the volume of local production. The problem of environmental pollution by pharmaceuticals and endocrine disruptors is increasingly being covered at the international level. It has been studied that pharmaceuticals, as well as endocrine disruptors, even at very low concentrations $(\mu \mathrm{g}$ / 1 and ng / 1), have an extremely negative impact, deteriorating the public health and the functioning of the human body and the ecosystem.

The provision of medicines and medical products is the first stage of health insurance, through which the insured person can obtain them for partial payment.

In the EU, the basic documents in the pharmaceutical field are the Directive 2001/83 / EU and the Regulation $726 / 2004$ of the European Parliament and of the EU Council which regulate the issue of obtaining the permission for the access to the market (similar to a registration certificate in Ukraine), obtaining a license for manufacturing and import, wholesale in medicines, as well as control in the course of circulation, including pharmacological supervision, etc.

Demographic aging, the increasing prevalence of chronic diseases, the availability of low-cost treatment, and the emergence of new quality life-enhancing medicines - all these factors underpin the growth of medicine consumption in the European region. The need for many of the most commonly used medicines has grown, at least partially, against the backdrop of the complex relationship between the change in the human lifestyle and the environment. For example, increased consumption of statins and anti-diabetic medicines may be associated with the proliferation of a sedentary lifestyle caused by urbanization; and the deterioration in the health of people suffering from respiratory diseases may be related to air pollution.

The consumption of certain groups of medicines has increased recently, which testifies to widespread changes both in the demographic situation and in the people's lifestyle. In some countries, the use of medicines for preventive purposes has become widespread. For example, after analyzing biomarkers - they are used to estimate the likelihood of certain diseases development medicines are often prescribed even when the health risks are relatively low. Many countries export waste for which they do not have the proper treatment/disposal method. The export option applies to certain types of waste (for example, pharmaceutical waste), but the export of infectious waste is not possible due to a variety of reasons, including health risks, logistics, and costs.

Non-steroidal anti-inflammatory drugs (NSAIDs) are consumed by millions of people worldwide. In the United States, more than 1 billion prescriptions are issued per year for the purchase of non-steroidal anti-inflammatory drugs.

In the Member States of the European Region, there is widespread recognition of the need for measures aimed at reducing environmental risks and ensuring the rational use of medicines. Taking into account that about 25.000 people in Europe die each year from antibiotic-resistant bacteria, it is equally important to recognize that strategies aimed at preventing antibiotics from entering the environment are capable of holding back the further development of resistance to antimicrobial medications.

At present, the EU pharmaceutical market is estimated at more than $\$ 140$ billion, and it has a very high potential for development. There is some regional segmentation in the European pharmaceutical market. Three countries, Germany, France, and the UK are the leaders in the market. Their total sales make up more than $55 \%$ of the market, and the consumption of medicine there is the highest. The comparison of the countries on the consumption of medicines is presented in Fig. 1.

Germany is the leader in terms of consumption in 2016 , with a volume of 82 million $\mathrm{kg} / \mathrm{year}$, followed by France with 62.3 million $\mathrm{kg} /$ year.

For visual statistics, one can cite the developed European country of Germany where 836 tons of acetylsalicylic acid, 622 tons of paracetamol, 345 tons of ibuprofen, and 86 tons of diclofenac were used in 2016. The population at that moment was 82.18 million people. This data takes into account the number of products sold and given on prescription. 


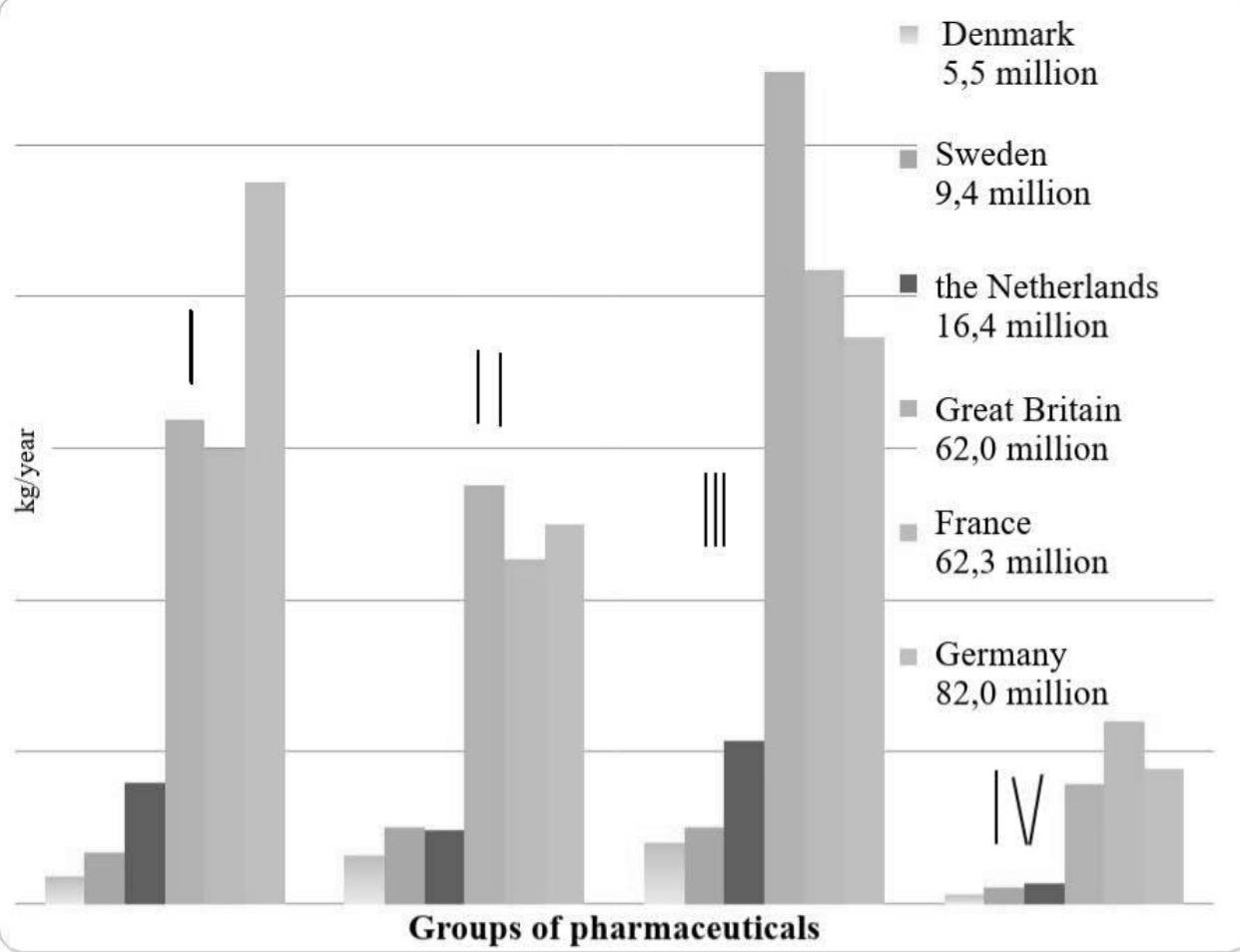

Fig. 1. Basic data on annual consumption of certain groups of medicines in different countries of the world (2016) I - antidiabetic, II - antidepressants; III - anticholesterol; IV - antibiotics

Pharmaceutical industry waste, such as medical and pharmaceutical waste entering the environment and wastewater, damage the ecosystem. The number of new medicines is increasing every day, as well as their consumption. Thus, the amount of waste from medical institutions is increasing. Medical waste is only $2-3 \%$ of the total amount, but it is considered the most hazardous. It may contain dangerous infectious bacteria that can cause epidemics.

With the increase of medicines worldwide, the possibility of medical and pharmaceutical waste entering the environment and water bodies is increasing. Therefore, it is important to address the problem and search for its solution.

The treatment of medical waste is a task that requires an extremely high level of attention and carries great risks related to the management of this medical waste. But the process of disposal and destruction of medical waste can entail the release of a large number of hazardous substances: both dumping at landfills and incineration must be carried out in accordance with ecological rules and regulations in accordance with the law of Ukraine. The process of medical waste burning releases strong pollutants into the atmosphere, carcinogens are furans and dioxins from chlorine halogen compounds, namely the hazardous materials dumping that contain heavy metals, and are likely to cause bioaccumulative hazardous substances transfer to the environment.
The most common methods of disposal and treatment of medical waste in Ukraine are:

1) Incineration of medical waste in furnaces.

2) Sterilization of waste with the help of water vapor at high temperature using technical apparatus autoclaves.

3) Chemical disinfection. The method is to disinfect objects solely by chemical means.

4) Disinfection of medical waste with microwaves. The process consists of grinding medical waste, thus reducing the amount of waste and mixing it with water.

5) Method of sterilization by infrared, radioactive and ionizing radiation. This method has not yet been sufficiently researched in the pharmaceutical field and has a major drawback - the threat to human health.

The research has previously proved that a few medicines coming from the wastewater, primarily from hospitals, have a very negative impact on the water bodies. Groups of medicines that are poorly soluble in water have been studied. They are anti-inflammatory, analgesic, antibiotics, hormones, cholesterol-lowering, and highly soluble medicines.

In the studies conducted in Austria, England, Greece, Italy, Spain, the Netherlands, Germany, and Switzerland, the residues of more than 82 types of pharmaceuticals and medicinal metabolites were revealed in the wastewater and surface water. Also, concentrations of a great number of different class pharmaceuticals in the dimension of $\mu \mathrm{g} / 1$ were detected in the samples selected below the sewage from the treatment plants. This leads to the 
conclusion that all these chemicals have a very significant and extremely high distribution, as well as good resistance.

During the research of the treatment plant in Lithuania, 5 types of antibiotics were found (norfloxacin, ofloxacin, ciprofloxacin, sulfadimethoxine, and sulfamethoxazole). Later, some of these antibiotics were also found in vegetables - carrots and potatoes. Their concentration was higher than the norm.

A lot of water bodies are contaminated with pharmaceutical waste. 25 pharmacological products have been identified in the River Lee, the UK. 26 residual pharmacological substances have been found in Germany at the outlet of the sewage from the treatment plants at concentrations sufficient to detect them.

Similar studies have been conducted around the world in Catalonia, Spain; Zurich, Switzerland; the Po and the Limpopo Rivers, Northern Italy. The same general conclusion has been made that water bodies contain much medical waste which is easy to diagnose. First of all, many questions are posed about the toxicity and harmful direct and indirect impact of these substances on the human body, and on the environment as a whole.
Pharmaceutical waste realizes its toxic impact on living organisms by different mechanisms. There may also be the development of resistant bacteria after water saturation with antibiotics. However, contact with one type of antibiotic sometimes leads to the emergence of broad-spectrum antibiotic genes that cause resistance to a wide range of antibiotics. Thus, during the research, bacteria that were resistant to macrolides, sulfanilamides, and tetracyclines were found. The rate of resistant bacteria development is determined by external conditions and the level of water pollution. In Sweden, this figure is $6 \%$, in Italy $17 \%$, and in the UK it reaches $22 \%$.

Both acute and chronic effects from the pharmaceutical wastes influence different organisms (phytoplankton, benthos, zooplankton, fish) have been analyzed. It was found that the concentration of substances in water is still low and incapable of causing acute effects, but such concentration is more than sufficient to provoke chronic diseases. Among the substances, the concentration of which exceeds the threshold of provoking chronic diseases, fluoxetine, propanolol, diclofenac, and carbamazepine are worth mentioning.

\section{Concentration of pharmaceutical substances (C) in the wastewater of hospitals in Europe and the coefficient of treatment at the treatment plants in the European countries}

\begin{tabular}{|c|c|c|c|c|}
\hline $\begin{array}{l}\text { The name of the } \\
\text { pharmaceutical substance }\end{array}$ & $\begin{array}{c}\mathrm{C} \text { in wastewater at treatment } \\
\text { plants (in the European } \\
\text { countries), } 10^{-6} \mathrm{~g} / 1\end{array}$ & $\begin{array}{l}\mathrm{C} \text { in the wastewater } \\
\text { of hospitals in } \\
\text { Europe } 10^{-6} \mathrm{~g} / 1\end{array}$ & $\begin{array}{c}\mathrm{C} \text { in the } \\
\text { wastewater of } \\
\text { hospitals of } \\
\text { Sweden, } 10^{-6} \mathrm{~g} / \mathrm{l}\end{array}$ & $\begin{array}{c}\text { Coefficient of } \\
\text { purification } \\
\text { on treatment plants } \%\end{array}$ \\
\hline Diclofenac & 10 & 70 & 3 & 34 \\
\hline Beta-estradiol & 0.114 & 0.23 & 0.38 & 30 \\
\hline Atenolol & 0.800 & 122 & 0.017 & 71 \\
\hline Furosemide & 2.214 & 21.5 & 40.2 & 42 \\
\hline Cefuroxime & 0.125 & 125 & 63.2 & - \\
\hline
\end{tabular}

Table 1 shows the concentration of pharmaceutical substances $(\mathrm{C})$ in wastewater from hospitals in Europe and the coefficient of purification at the treatment plants in the European countries. As can be observed, the largest pollutant of wastewater at the treatment plants is a pharmaceutical substance of diclofenac, the concentration of which is $10 \cdot 10^{-6} \mathrm{~g} / \mathrm{l}$. The highest purification ratio at the treatment plants is $71 \%$ of the atenolol substance (selective blocker). The highest rate in wastewater from hospitals in Europe is the concentration of atenolol, which is $122 \cdot 10^{-6} \mathrm{~g} / \mathrm{l}$.

In Ukraine, the problem of collection and disposal of medical waste has not yet been solved. The State Sanitary rules and norms "Rules on the collection, storage, and disposal of waste from medical and preventive treatment institutions" are at the stage of their approval. It means that the one who generates waste, that is, all the hospital staff, is primarily responsible for the disposal of hospital waste. Nowadays, for the disposal of medical waste, it is recommended to use stand-alone incinerator installations of the "IN-50" type, because they contribute to a significant reduction in the $(90-95 \%$ of the original volume) and $100 \%$ disinfection from pathogenic microorganisms and toxic organic compounds.

Pharmaceuticals contaminate the environment and wastewater, which are thoroughly purified at the treatment plants and can accumulate in activated sludge.

To effectively solve the problem of utilization and treatment of medical waste in Ukraine, it is necessary to pay much attention, as well as understand the set problem of the medical waste negative impact on the environment. When choosing a technology for the treatment of medical waste, it is necessary to consider the efficiency of work, ecological, financial, and organizational capabilities of their processing 
technology. Namely, the following requirements should be considered:

- Reduction of all possible risks to the population, such as possible injuries from needle prick and the impact of pathogens;

- Making smart and efficient decisions on the treatment of medical waste;

- The possibility of technical inadequacy of the existing technology in the healthcare sphere.

The expired pharmaceuticals belong to one of the most specific categories of waste as they are extremely harmful to the environment and people when utilized incorrectly.

The pharmaceutical industry waste, such as medical and pharmaceutical waste entering the environment and wastewater, negatively affects the ecosystem. The number of new medicines is increasing every day, as well as their consumption. Thus, the amount of waste from medical institutions is also increasing. Medical waste is only $2-3 \%$ of the total amount of waste, but it is deservedly considered to be the most hazardous. It may contain dangerous infectious bacteria that can even cause epidemics.

Recycling of medical waste is a task that requires an extremely high level of attention and carries great risks associated with medical waste handling. But the process of disposal and destruction of medical waste can entail the release of a large number of hazardous substances: both dumping at landfills and incineration must be carried out following the ecological rules and regulations under the law of Ukraine. When medical waste is burnt, strong pollutants are released into the atmosphere - carcinogens, furans and dioxins from chlorine halogen compounds, namely dumping of the hazardous material that contains heavy metals, and is likely to cause bioaccumulative hazardous substances to transfer into the environment.

In the EU countries, the schemes of collecting the unused pharmaceuticals are ineffective, and too many pharmaceuticals have unjustifiably appeared in the environment, particularly in water bodies. Not all European citizens know how to utilize the unwanted medicines safely. EU lawmakers must take urgent actions to address this global environmental problem.

The research has previously proved that a small number of medicines coming from wastewater, primarily from hospitals, negatively influence water bodies. Groups of medicines, poorly soluble in water, have been studied: antiinflammatory, analgesic, antibiotics, hormones, cholesterollowering, and highly soluble medicines.

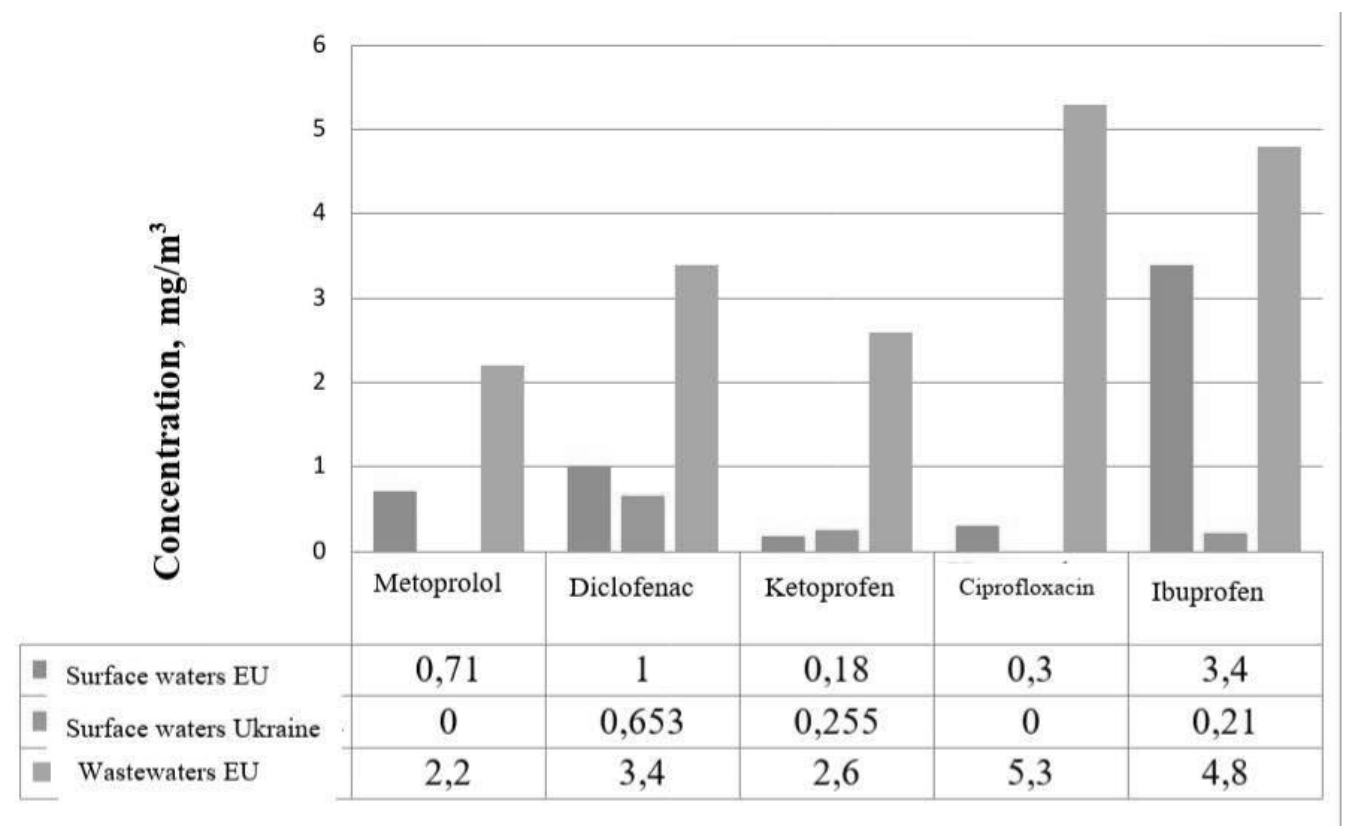

Fig. 2. Comparison of pharmaceuticals concentrations in surface and wastewater in 2016

According to the diagram in Fig. 2, we see that the highest concentration in the EU surface water is ibuprofen - $3.4 \mathrm{mg} / \mathrm{m}^{3}$, and in the EU wastewater ciprofloxacin $-5.3 \mathrm{mg} / \mathrm{m}^{3}$ and ibuprofen $-4.8 \mathrm{mg} / \mathrm{m}^{3}$.

Most of the pharmaceuticals coming into the wastewater are from the hospitals. This is especially true of large cities with a population of over 620,000 inhabitants. Most often, these cities include a large number of hospitals and treatment facilities where a lot of pharmaceuticals are used to treat seriously ill patients.

\section{Experimental part}

Along with the problem of waste treatment, packaging for pharmaceutical products is important.

A pharmacy warehouse was selected as an object of the experimental study. 
The empirical, visual, and graphic methods were used to investigate an enterprise where the waste of the pharmaceutical industry is possible and the way for its recycling was suggested.

The purpose of this study was to determine

- the quantity of unsuitable packaging (waste);

- the amount of the packaging that is shipped from the warehouse to pharmacies and customers;

- places for storage of the packaging and the auxiliary materials in the warehouse, its weight;

- the possibility of the advent of counterfeit medicines in the warehouse, as well as their number;

- the balance of the expired drugs and their handling;

If we talk about the activity of the enterprise, it is engaged in retail trade of pharmaceuticals, wholesale of pharmaceutical goods, wholesale of other household goods. The enterprise has 26 pharmacies. There are another 29 branches across the region. Pharmacies are located in the large sleeping areas of the cities, or at medical and preventive treatment institutions.

Pharmacy warehouse has 3 working departments:

- department of galenics (ampoules, solutions and medical products);

- VAT department (baby nutrition);

- department of pills.

\section{The results of the experiment}

During the 3 months (August, September, October 2019), the enterprise was monitored, and the following results were obtained regarding the set tasks.

All containers for medical products and medicines are transported by drivers to the pharmacy warehouse in 3 types:
1) multi-turn packaging for medicines packing;

2) multi-turn disassembled packaging (boxes to be glued);

3) unsuitable packaging (non-packable boxes).

The amount of packaging unsuitable for work was calculated in 3 departments during the month:

- department of galenics (ampoules, solutions and medical products) - 43 units;

- $\quad$ VAT department (baby nutrition) - 15 units;

- $\quad$ department of pills - 27 units.

The main tasks of pharmacy warehouse staff are:

- storage of medicines in such a way as to prevent their deterioration;

- collecting goods according to the provided invoices;

- observance of rules of medicine packing;

- timely shipment of goods to their destination (pharmacies, pharmacy branches).

The packaging sent from warehouses to pharmacies, pharmacy branches, and wholesale customers was also calculated at the departments every day for one month in 2019. The following results were obtained:

1) department of galenics - 5123 boxes;

2) VAT department - 3284 boxes;

3) department of pills -2742 boxes.

As we can see, the largest amount of packaging for the given period was sent by the galenics department and this is explained by the fact that the number of orders during the month was the highest among the 3 departments.

In Fig. 3, 4, 5, the amount of packaging sent is compared at 3 departments (galenics, VAT, and pills) within a month.

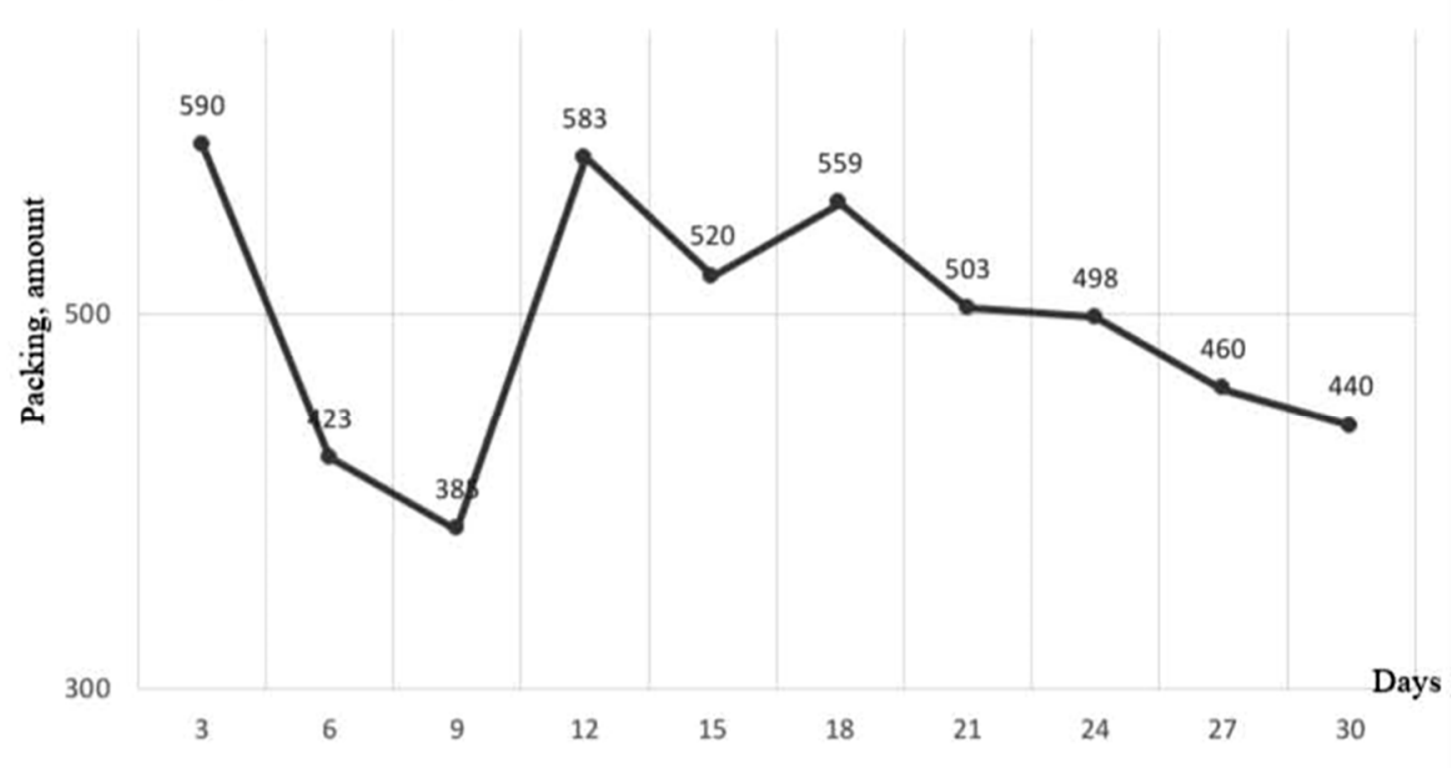

Fig. 3. The amount of packaging collected by the department of galenics 


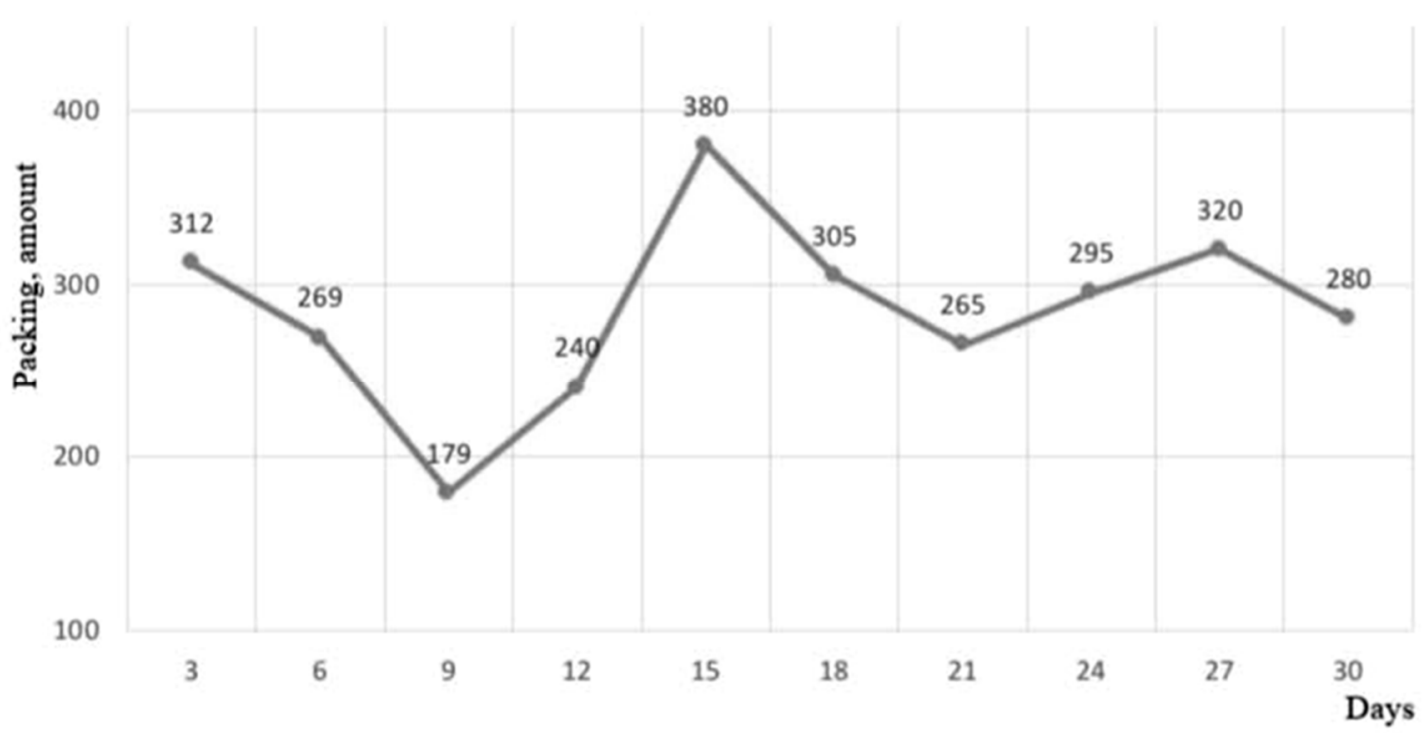

Fig. 4. The amount of packaging collected by the VAT department

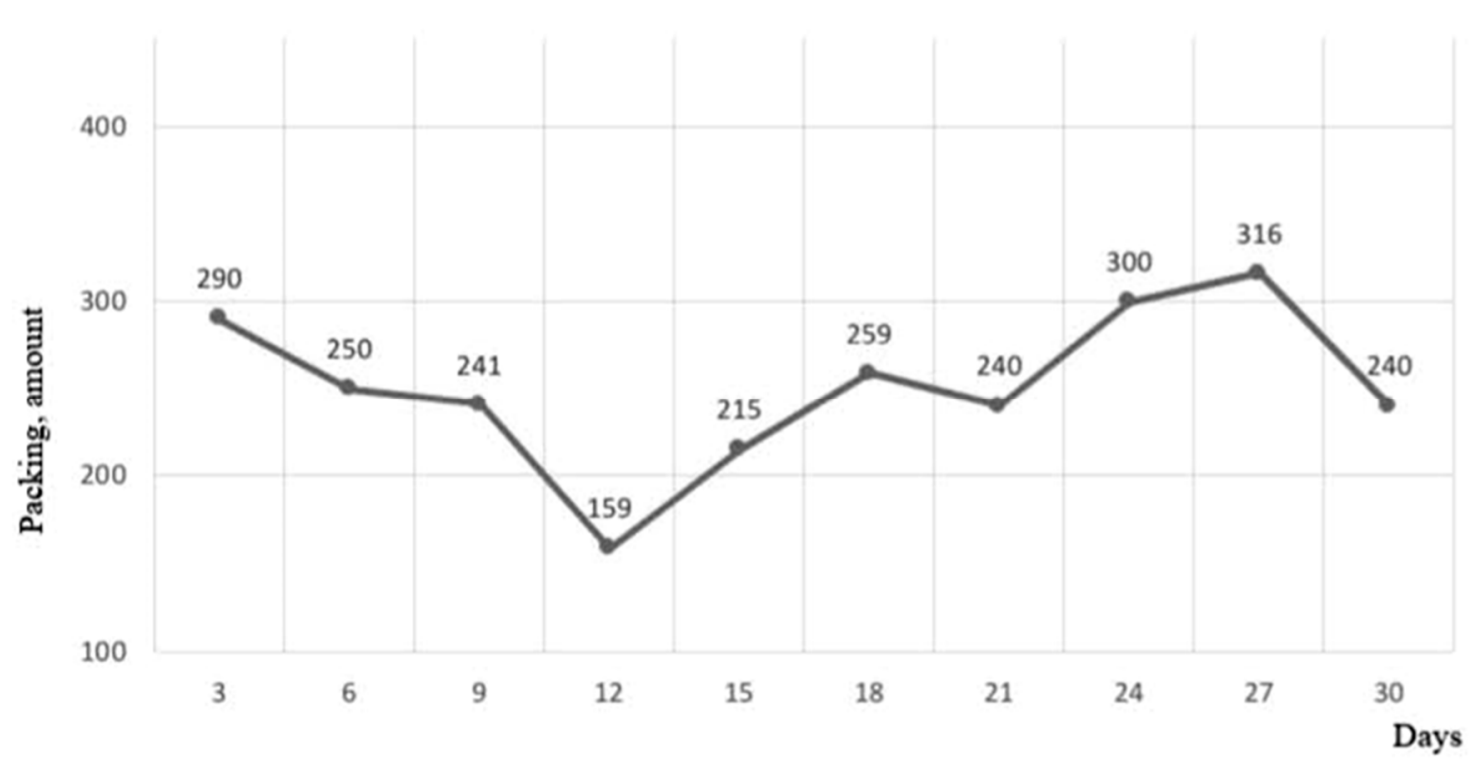

Fig. 5. The amount of packaging collected by the department of pills

Let us compare the histograms at 3 departments:

1) the largest amount of packaging collected in 3 days: galenics -590 boxes, VAT - 380 boxes, pills 316 boxes;

2) the least amount of packaging collected in 3 days: galenics -385 boxes, VAT -179 boxes, pills -159 boxes;

3 ) in all 3 figures, we may see that there is a sharp decline in the number of packaging collected at the end of the month. This is because pharmacies and pharmacy branches are not interested in large orders, as they calculate the balance of goods at the end of each month.

The production premises are primarily allocated for the storage of different groups and types of medicines, medical products, as well as packaging and auxiliary materials.

Counterfeit medicines are medicines that are made with violation of the established labeling requirements, the origin of which may be hidden or not consistent with reality. There is, of course, little possibility for the counterfeit medicines to get to the warehouse, but it still exists. During the experiment, it was determined that 2 goods did not meet the marking requirements. It means, they were falsified 1 pack of ampoules and 1 medical device were manufactured in the wrong composition and without the active substance in the ampoules. 
The expired pharmaceuticals belong to one of the most specific categories of waste, as they are extremely harmful to the environment and people when improperly utilized. In Fig. 6, there is one way to solve the problem with the expired medicines.

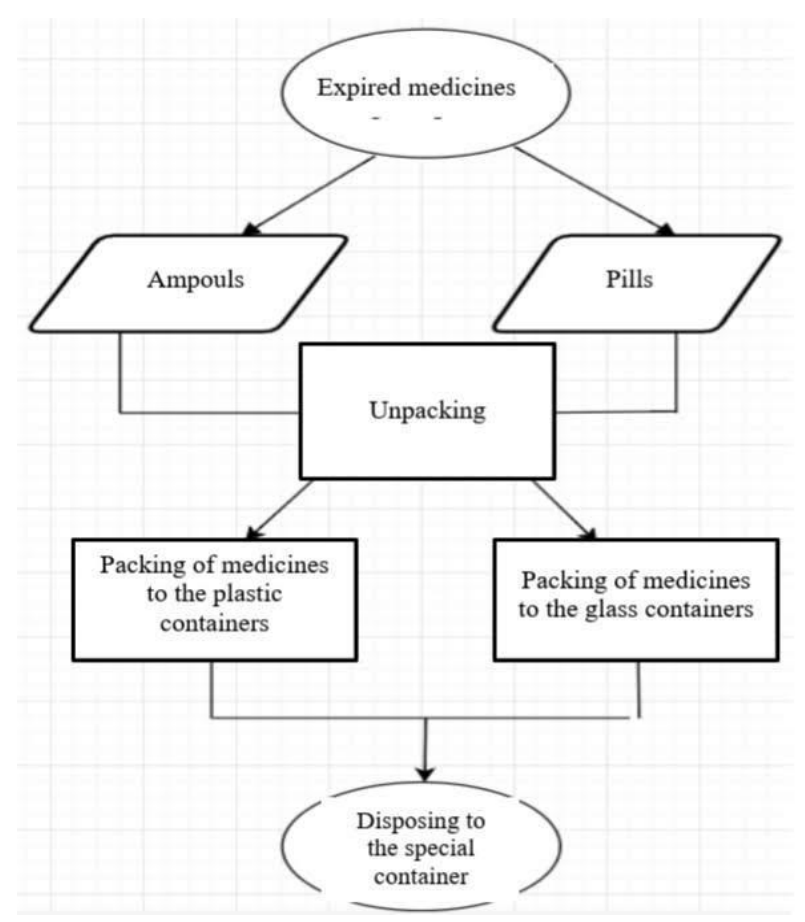

Fig. 6. Block diagram of the expired medicines disposal

The expired pills, ampoules, and capsules should be unpacked from their original packaging, then repacked in plastic or glass containers and sealed tightly. After that, they can be disposed in a special container, which must be properly labeled.

One of the variants to solve the problem was suggested above - a block diagram of the disposal of expired medicine. The disposal of medicines is an important problem of our time that requires an immediate solution.

\section{Conclusions}

To address the issue of safe handling the waste in the pharmaceutical industry, in particular, poor quality and expired medicines, it is advisable to take the following measures:

1. Establish the systems for collecting low-quality and expired medicines from the population to prevent their uncontrolled entry into the environment and further neutralize them.
2. Introduce and use in production optically pure therapeutic isomers to reduce the side effects of medicines and a negative impact on the environment.

3. Collect the expired medicines and ensure their safe disposal both at the enterprise and at home.

Water pollution by pharmaceuticals in the EU countries is an urgent global problem nowadays due to the increase in the consumption of medicines containing active pharmaceutical substances.

A lot of pharmaceuticals under study, both in surface and wastewater, are at very low concentrations, but.even at low levels, they have a very negative impact on the environment and the ecosystem as a whole.

The methods of purification of pharmaceutical compounds in Ukraine and the EU countries have recently been widely and effectively used, in particular, the processes of electrochemical and biological purification, filtration and coagulation, oxidation and adsorption.

\section{References}

[1] Akymenko Yu. V., Kazi K. Sh., Kolesnikov S. I. Mazanka M. S.: Ecological effects of the environment contamination by antibiotics. Science Center of the Academy of Sciences, 2013, 3, 1196 (in Ukrainian).

[2] Balashov A. I. Formation of the mechanism of pharmaceutical industry sustainable development: theory and methodology. Publishing house: HUEF, 2012. (in Ukrainian).

[3] Vystavna Yu. Yu.: Pharmaceuticals in natural waters: monitoring and ecological risk. Communal services, 97, 134 (in Ukrainian).

[4] Hurynovych A. D., Voronovych N. V.: Visn. of Brest State Technical Univ., 2012, 2, 21 (in Ukrainian).

[5] Hurina I. V.: Medicine of Ukraine, 2014, 51-54 (in Ukrainian).

[6] Yermakovych I. A., Samoylenko N. M.: Visn. Vinnytsia Polytechnic Institute, Vinnytsia, 2015, 5, 26 (in Ukrainian).

[7] Zaliska O. M. Theoretical bases and practical use of pharmacoeconomics in Ukraine (doct. thesis), Lviv, 2004, 121 (in Ukrainian).

[8] Koynova I., Kovpak D.: Visn. Lviv Univ., 2009, 19 (in Ukrainian).

[9] http://www.apteka-puls.com/puls-357.html

[10] Mesarosh R., Baran' Sh.: Water and water treatment technologies. Scientific and technical news. № 4 (10), 2012, (11), 2013, 25 (in Ukrainian).

[11] Popovych O. R., Yatchyshyn Yu. Y., Maliovanyi M. S. et al.: Bull. Lviv Polytechnic National Univ.: Chem., technol. of substan. and their appl., 2008, 622, 60 (in Ukrainian). 